Etnográfica

Revista do Centro em Rede de Investigação em

Antropologia

vol. 24 (1) | 2020

Vol. $24(1)$

\title{
Poética e política nas terras baixas da América do Sul: a fala do chefe
}

Poetics and politics in Lowland South America: the chief's speech

\section{Pedro de Niemeyer Cesarino}

\section{(2) OpenEdition}

Journals

Edição electrónica

URL: https://journals.openedition.org/etnografica/8109

DOI: 10.4000/etnografica.8109

ISSN: 2182-2891

\section{Editora}

Centro em Rede de Investigação em Antropologia

\section{Edição impressa}

Data de publição: 1 fevereiro 2020

Paginação: 5-26

ISSN: 0873-6561

\section{Refêrencia eletrónica}

Pedro de Niemeyer Cesarino, «Poética e política nas terras baixas da América do Sul: a fala do chefe», Etnográfica [Online], vol. 24 (1) | 2020, posto online no dia 25 fevereiro 2020, consultado o 20 janeiro 2022. URL: http://journals.openedition.org/etnografica/8109 ; DOl: https://doi.org/10.4000/ etnografica. 8109

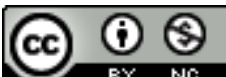

Etnográfica is licensed under a Creative Commons Attribution-NonCommercial 4.0 International License. 


\section{Poética e política nas terras baixas da América do Sul: a fala do chefe}

\section{Pedro de Niemeyer Cesarino}

Este artigo é dedicado à noção de política envolvida nas falas de chefe das sociedades ameríndias das terras baixas da América do Sul. Através da comparação com etnografias diversas, pretende-se compreender os contornos de um gênero verbal marcado pela ênfase na intensidade da performance e por um rendimento especial do significado. Busca-se, com isso, delinear os contornos da relação entre política, xamanismo e regimes de enunciação.

PALAVRAS-CHAVE: fala de chefe, política ameríndia, poética, performance, enunciação.

Poetics and politics in Lowland South America: the chief's speech • This paper aims to explore the politics involved in the chief's speech in Amerindian societies of Lowland South America. A comparative approach of ethnographic studies will be mobilized to understand a verbal genre characterized by an emphasis in ritual intensity and by a special production of meaning. The objective is to apprehend Amerindian interrelations between politics, shamanism and modes of enunciation.

KEYWORDS: chief's speech, Amerindian politics, poetics, performance, enunciation.

CESARINO, Pedro de Niemeyer (pncesarino@usp.br) - Departamento de Antropologia, USP, Brasil. 


\section{A ÉTICA DA DIALOGICIDADE}

A política ameríndia (vista a partir das terras baixas sul-americanas) se estabelece a partir de um certo regime de discurso que apresenta desafios conceituais diversos. Comuns entre muitas sociedades, as falas de chefe constituem um gênero privilegiado de tal regime, que se estabelece em ocasiões de encontro ritualizado entre afins. Tais palavras, entretanto, são desenvolvidas através de uma poética singular, sobre a qual não é a capacidade argumentativa que se enfatiza nem, tampouco, o significado pleno do discurso, mas sim um modo de significar especialmente atrelado ao ritmo (Meschonnic 1982) e à intensidade da performance. A partir da análise de estudos etnográficos diversos dedicados às falas de chefe, pretende-se aqui oferecer algumas reflexões sobre os modos ameríndios de significação e de enunciação de uma política possível. Para além das performances rituais particulares em que ocorrem, as falas de chefe se inserem em um ambiente de dialogicidade mais amplo que parece rechaçar, de maneira sistemática, o uso da voz autoritária. Comecemos, portanto, por uma descrição preliminar de tal ambiente.

Nas reuniões políticas realizadas por povos ameríndios, é comum observar o respeito pelo tempo da fala do interlocutor, raramente interrompido ou silenciado. Como o tempo da palavra alheia é soberano, reuniões e discussões não possuem um término claro e podem durar indefinidamente; parecem, mais ainda, não ser pautadas pela necessidade de estabelecer alguma decisão final. A sucessão dos discursos, entretanto, é apenas aparentemente monológica, já que estará sempre acompanhada de channel back responses, de expressões padronizadas que transmitem a atenção da audiência ao que se diz. Ainda que variem em suas reflexões, os discursos (proferidos geralmente por pessoas de proeminência nas sociedades, tais como anciãos e anciãs, chefes e lideranças) partilham de uma forma geral comum, muitas vezes marcada por um ritmo específico que praticamente os transforma em uma arte da palavra perfeitamente compatível com a cacofonia produzida pela movimentação de corpos, crianças e demais atividades prosaicas que competem com o evento aparentemente solene.

Essas observações gerais já seriam suficientes para perturbar as formas ocidentais de concepção e prática do discurso político. Mesmo no mais democrático dos ambientes, o direito de todos à palavra precisa ser garantido por um código de leis. Esse pressuposto de um espaço político abstrato e comum remonta às noções gregas de meson, o ponto geométrico central tomado como referência pela isegoria, o direito de todos à palavra, e pela isonomia, o direito de todos à lei (Wolff 1983). De contrário, os falantes fatalmente atropelariam o limite garantido pela lei comum, avançariam uns sobre os outros, interromperiam argumentos ainda não concluídos, lançariam mão de todos os artifícios para fazer valer a sua posição em detrimento da alheia. Em última instância, descambariam para as ofensas e outras formas de anulação total de outrem. 
$\mathrm{Na}$ ausência de alguém que controle tempos e dimensões das falas públicas (moderadores, relógios, regimentos), os interlocutores ameríndios parecem, por sua vez, lançar mão de um acordo de fundo, de uma espécie de entendimento tácito sobre o respeito à posição de um sujeito de discurso.

Entre os marubo (falantes de pano do vale do Javari, no Amazonas), um padrão é notável. Ao término da fala de uma determinada pessoa (por exemplo, um parente mais velho que transmite ensinamentos através de um gênero específico de discurso, a ese vana, ou "fala de ensinamento"), o destinatário, mesmo que contrariado, jamais retrucará de imediato com palavras ofensivas. Dirá, antes de tudo, algo do tipo: "Você falou e eu escutei, você terminou de falar e eu compreendi o que você disse, o que você disse não é mesmo muito ruim, eu escutei e agora vou dizer o que penso". Em seguida, o interlocutor começa com sua fala, que deverá necessariamente terminar com um fechamento formular do tipo: "Já chega, era isso mesmo que eu tinha a dizer", ou então, "Assim eram mesmo as falas dos nossos antepassados, assim é mesmo também o que estou dizendo agora". ${ }^{1}$

Esse entendimento tácito sugere uma ética da dialogicidade presente no cotidiano e, de maneira ainda mais evidente, em situações tais como grandes reuniões interétnicas e encontros ritualizados entre grupos locais. Tal ética parece estabelecer vínculos com o sentido das falas de chefe que estudaremos aqui, bem como com outros modos verbais que compreendem narrativas míticas, marcadas pela partilha das decisões relacionadas aos processos de formação do mundo nos tempos antigos (Cesarino 2013, 2014). Uma característica central das enunciações ameríndias é o uso predominante do discurso direto, no qual as falas de outrem são sempre resguardadas ou reproduzidas na íntegra e acompanhadas de modalidades epistêmicas reportativas (ou hearsays). Numa cadeia de transmissão de conhecimentos verbais, tais como narrativas míticas e ensinamentos, o uso do discurso direto é estratégico para garantir a autoridade do falante através de uma outra autoridade mais remota, aquela de um antepassado ou de alguma outra fonte primeira do conhecimento narrado. Por vezes, uma narrativa mítica inteira pode ser atribuída a um locutor mais velho e o discurso sempre levará em seu final algum marcador reportativo. Noutras, o relato de uma experiência extraordinária (encontro com espíritos, transformação em pajé, encontro com brancos, etc.) é que será atribuído a um outro falante e também devidamente marcado ao longo de sua execução. ${ }^{2}$

l Para um estudo sobre reuniões e relações entre política e gêneros de discurso entre os marubo (que, no entanto, não trata dos diálogos tsãiki que consideraremos adiante), consultar Ruedas (2002).

2 Em seu estudo sobre as artes verbais dos sharanawa da Amazônia peruana, Pierre Déléage (2009) denominou de maneira instrutiva essa diferença entre os modos de produção de verdade (que, frequentemente, produzem interpolações complexas) de "ostensão", quando se refere à informação validada pela experiência direta do locutor, e de "deferência", quando trata da informação validada pela experiência de outrem. 
Em outros casos ainda, o discurso direto dá margem àquelas complexas construções polifônicas características de cantos xamanísticos, nas quais vozes de locutores diversos se embutem umas nas outras (mas são necessariamente preservadas em sua íntegra) e se reúnem em um ponto virtual de enunciação, que corresponde ao corpo do xamã ou pajé cantador (Cesarino 2011 ; Castro 1986; Heurich 2015). O uso do discurso direto é, portanto, um dispositivo central dos xamanismos ameríndios, pois garante que a palavra alheia seja reproduzida na íntegra e, portanto, conhecida por outros destinatários distantes do evento testemunhado diretamente pelo xamã que viaja alhures. O xamã, como dizia Manuela Carneiro da Cunha (1998), faz aí o papel de diplomata do cosmos e, de acordo com a metáfora constante nas terras baixas, opera como se fosse um "rádio", ou seja, um espaço através do qual repercute a polifonia sociocósmica. É a partir desse espaço de neutralidade, de preservação da palavra do outro em sua íntegra, que os ouvintes de uma determinada sessão ritual poderão conhecer os conflitos que ocorrem em outras posições e traçar as suas reações. No caso do xamanismo marubo, eles saberão, por exemplo, se tal ou tal desafeto de uma pessoa doente enviou este ou aquele espírito agressor para atacá-la ou para capturar seu duplo (vaká) em algum momento de liminaridade. A partir daí, elaborarão algum contra-ataque que, por vezes, adquire as proporções de uma verdadeira batalha cósmica, com legiões de espíritos auxiliares se lançando contra outros espíritos agressores através de suas armas, ventanias, incêndios, onças gigantes e outros recursos invisíveis aos olhos da audiência (cf. Cesarino 2011 ). Os xamãs rezadores marubo, entretanto, insistiam frequentemente em me dizer que pretendiam antes "ensinar" (esea) os espíritos agressores com seus cantos, e não "brigar" (vatxia a), empregando assim a mesma distinção usada por alguém que aconselha um parente insensato.

\section{AS FALAS DE CHEFE}

Essa digressão inicial deve servir para manter em mente alguns princípios centrais dos regimes ameríndios de dialogicidade que permeiam as artes verbais mais diretamente relacionadas ao xamanismo, tais como os cantos que lhe são próprios: o uso do discurso direto livre, de sua consequente polifonia, demarcada pelo uso de evidenciais e, portanto, por um modo específico de produção de sentido que posiciona os enunciadores de maneira horizontal ao longo da performance verbal. É essa maneira de se resguardar ou, antes, de elaborar e produzir a posição de outrem (a saber, de um enunciador atual ou virtual) que me interessa mais especificamente aqui. Ela possui um momento emblemático e à primeira vista paradoxal, que é o dos encontros ritualizados marcados por confrontos verbais, entre os quais se destacam as falas de chefe, apenas aparentemente apartadas do xamanismo (Luciani 2017; Guerreiro 2015). No caso marubo, assim como em outros, não é essa recursividade enunciativa 
(garantida pelas partículas reportativas) que se faz presente, mas sim todo um outro conjunto de evidenciais responsável pela atribuição de autoridade a uma fonte mais antiga que é tomada como referência pelo enunciador. ${ }^{3} \mathrm{Um}$ dos aspectos intrigantes de tais confrontos dialógicos está no aparente predomínio da função fática em detrimento da função referencial, justamente lá onde esperaríamos encontrar um emblema da interlocução política entre iguais e/ou entre rivais. É nessa direção que Greg Urban oferece uma tentativa de síntese dos diálogos cerimoniais nas terras baixas, a partir de cinco casos etnográficos (wayana, jívaro, yanomami, shokleng e kuna):

"Em todos os casos, os diálogos cerimoniais enfatizam a dialogicidade pragmática em articulação com a resposta pragmática que sinaliza a compreensão, ao mesmo tempo em que estimulam o falante-líder a continuar. Os diálogos não vinculam de forma alguma o interlocutor ao conteúdo semântico expresso. Por conta de sua saliência, o ciclo pragmático de resposta se torna ele mesmo um veículo de significação. Ao imitar a conversação ordinária, na qual as channel back responses desempenham um papel constante, ele também se transforma em um 'modelo' de procedimento de conversação - em particular da conversação que está em jogo” (Urban 1986: 378). ${ }^{4}$

Vejamos ainda como Urban compreende o sentido geral de tais diálogos, sem descartar o papel do significado (ou, antes, da articulação íntima entre performance e significado que parece ser responsável pela potência singular de tal gênero verbal e de seu valor metacomunicativo). Muito embora não aprofunde as consequências ontológicas do presente caso, Urban adianta na seguinte passagem um traço fundamental, a solidariedade e o reconhecimento da posição do outro, ao qual voltaremos mais adiante:

"Se a solidariedade consiste, por um lado, na coordenação das ações de uma pessoa com as de outra, tal como imaginadas no ciclo pragmático, ela é também, por outro lado, um reconhecimento positivo do outro, uma sinalização de que um reconhece as ações do outro e compreende seu 'significado'. Através da execução da resposta pragmática, os diálogos cerimoniais se transformam em um ícone do caráter semiótico geral de uma relação solidária. Simultaneamente, esses diálogos sugerem de modo indicativo que

3 Não tratarei aqui de outros tantos estudos etnográficos relacionados às falas de chefe, tais como os referidos por Guerreiro (2015: 63), e que partilham das principais características do gênero aqui comentadas. Seleciono antes um conjunto de três casos estratégicos (achuar, kuikuro e marubo) para desenvolver as questões do presente artigo.

4 São minhas todas as traduções para o português de citações que constem em língua estrangeira na bibliografia. 
a solidariedade está presente na interação linguística específica em que são empregados, ou seja, eles são também 'modelos de' solidariedade” (Urban 1986: 378).

Um dos mais famosos momentos em que tais gêneros verbais costumam ocorrer é o kwarup, ao longo do qual os grupos locais do alto Xingu, os ótomo, se encontram em uma determinada aldeia. Ao longo de tal encontro, são realizadas diversas anetü itaginhü, ou conversações de chefes, uma arte da palavra extremamente complexa que exige um longo processo de aprendizado. Trata-se de uma conversação formal que pressupõe e implica a interlocução, estabelecida através de sequências de fórmulas verbais estandardizadas. As conversações de chefes alto-xinguanas representam, segundo Bruna Franchetto, o "ícone sublime do encontro e da reciprocidade" (2000: 485) entre os diversos grupos locais. A autora, que possui um estudo detalhado sobre o assunto, apresenta da seguinte maneira alguns de seus aspectos mais significativos:

"Ela [a conversa de chefes] é também marcada por expressões autoderrogatórias e índices de neutralização do 'eu': [tais como] formas pronominais de inclusão coletiva ou que codifiquem uma distância social de afinidade, partículas epistêmicas que exprimem um saber que atravessa o locutor, manifestações de incerteza, neutralização da expressividade individual no ritmo e na versificação. Ainda assim, essas observações generalizantes do significado literal de elementos estilísticos não esgotam o sentido das 'conversações de chefes', que são um canal de expressão de intencionalidades particulares e um instrumento político importante. Nesse sentido, o 'escamoteamento da individualidade' é um recurso retórico, esteja em jogo a interação/afrontamento entre os ótomo ou a dor individualizada relativa ao seu próprio ótomo em momentos de agitação social. O anetü é, simultaneamente e de maneira ambígua, uma voz do bem comum, de seu próprio grupo e voz de si mesmo, do indivíduo de descendência 'nobre' que constrói seu status de chefia, e portanto, uma forma de trajetória política” (Franchetto 2000: 484).

As anetü itaginhü, diz ainda Franchetto, são difíceis de traduzir porque as frases completas costumam ser cortadas em unidades melódicas paralelas (esse tipo de arte verbal é, em geral, salmodiado ou entoado) e, também, por serem compostas de fórmulas marcadas pela "linguagem figurativa metafórica e erudita" (Franchetto 2000: 486). Isso, porém, não as transforma, de modo distinto do que propunha Pierre Clastres, em uma espécie de linguagem semanticamente vazia na qual predomina apenas a performatividade da função fática. O significado de tais conversações, de acordo com Franchetto, possui uma mensagem geral passível de ser apreendida em meio à sua aparente ausência de significado: trata-se da tentativa de reforçar uma certa continuidade com 
um passado, do qual o presente é apenas uma espécie de "réplica empobrecida" (Franchetto 2000: 493). É o que vemos abaixo em uma retradução livre minha de um trecho originalmente traduzido por Franchetto. Ele se refere à fala formal de um chefe que representa o ótomo convidado de um kwarup e se direciona aos mensageiros anfitriões. O evento se dá ainda na periferia da aldeia que oferece o kwarup, na qual os grupos convidados estavam reunidos. Em sua fala, o locutor se refere a determinados presentes que trouxe para os anfitriões através de termos que não pertencem à língua kuikuro cotidiana, mas sim ao léxico especial ritual:

"vós que fostes mensageiros

eu trago nossos filhos, ex-mensageiros

sim, em vão tudo ainda como sempre

eu trouxe meus filhos verdadeiros, tudo ainda como sempre

procure pelos chefes, tudo ainda como sempre

eu trouxe minhas coisas verdadeiras, tudo ainda como sempre

estou sentado para acolher os verdadeiros mensageiros, tudo ainda como sempre

diante do mestre da bebida, eu afirmo, tudo ainda como sempre

foi em seguida que conduzi minha gente, tudo ainda como sempre, eu digo

que veio até nós, tudo ainda como sempre

que veio até nós, tudo ainda como sempre

os colares de Aikakú, eu digo como sempre

os colares de Aikakú, eu digo como sempre

o arco negro, eu digo como sempre

o arco negro, eu digo como sempre

as facas de Kudjaitsi, eu digo como sempre

as facas de Kudjaitsi, eu digo como sempre

os colares de Inhasá, eu digo como sempre

os colares de Inhasá, eu digo como sempre"

Vemos aí como o texto é marcado pela configuração paralelística (distinta de uma mera repetição gratuita), onipresente nas artes verbais ameríndias (Cesarino 2006). Aqui, porém, o efeito paralelístico se dá pelo uso marcante do evidencial wãke, que Franchetto traduz por "encore comme toujours" (tudo ainda como sempre). É essa partícula que mostra como a continuidade entre passado e presente se dá através dos mesmos rituais, dos mesmos encontros, da mesma oferta de presentes, mas em uma atualidade empobrecida com relação aos outros tempos. Isso é bastante comum também entre outras sociedades ameríndias, nas quais ocorrem outros diálogos cerimoniais análogos ao anetü itaginhü alto-xinguano. Anne-Christine Taylor apresentou recentemente uma análise do discurso cerimonial entre os achuar: trata-se de um discurso aujmatin realizado na ocasião do ritual anemat, no qual dois grupos se encontram para 
travar uma aliança de guerra, tendo em vista um desafeto comum (Descola 2006: 427 e segs.). ${ }^{5}$ Passemos a esse caso.

O aujmatin jívaro é uma forma ritualizada de diálogo de enfrentamento agressivo, cujo conteúdo semântico parece ser vazio (mais uma vez, a função fática em detrimento da função referencial). A forma é marcada por frases cortadas pelo fluxo rítmico, sem aparente articulação lógica, reiterativas e pontuadas pelas channel back responses e, neste caso específico, pela ausência de reported speech e de dêiticos. Elas são também permeadas de alusões a situações sociais comuns e de fragmentos de narrativas que refletiriam sobre os momentos atuais, muito embora nunca haja uma referência direta e precisa a situações concretas. O diálogo, que se dá entre parentes potenciais, não resulta em uma hierarquização dos interlocutores e não possui vencidos e vencedores. Ele acontece no centro da maloca com os interlocutores alinhados face a face, os corpos rígidos e adornados, de certa forma inexpressivos no que se refere à possibilidade de revelar, através da gestualidade, seus estados de alma ou inclinações individuais. Trata-se, a rigor, de uma manifestação de magnitude individual, na qual as subjetividades dos interlocutores se alinham. É essa magnitude que garante a veracidade dos enunciados, como se o locutor dissesse dessa forma ser ele a fonte final de autoridade do que se comunica, por conta mesmo dessa opacidade de seu discurso performático. Não por acaso, o gênero verbal que sucede esse diálogo apresenta uma inversão simétrica de tais características. Neste outro gênero, traduzido por Taylor como "falar lento", a fala é dominada pela tópica da transparência (contrária à da opacidade que marcava o primeiro), caracterizada por um afrouxamento da rigidez corporal e da formalização verbal, sendo pautada pelos relatos de experiências visionárias que podem significar a potência predatória do emissor e sua possibilidade de "absorver" ou "apreender" o destinatário. Em um caso, temos, portanto, uma equiparação simétrica entre dois interlocutores, marcada por um discurso alusivo, genérico e impessoal em que a força de sua forma expressiva parece ser o traço central. Noutro, tal força performativa dá lugar à capacidade de convencimento pelo significado, que expressa a trajetória biográfica de um locutor inclinado a estabelecer uma influência assimétrica sobre seu oponente. Vamos olhar melhor para o primeiro gênero de discurso ritual achuar, mais próximo daquele estudado por Bruna Franchetto e, também, dos tsãiki marubo apresentados logo adiante. Em As Lanças do Crepúsculo, Philippe Descola (2006: 432-433) apresenta algumas traduções de tais diálogos, muito provavelmente os mesmos a que se referia Taylor. Portando uma arma embaixo do braço, na postura ritualizada de enfrentamento, o locutor $A$ entoa com força e firmeza os seguintes versos:

5 Neste parágrafo e seguintes, as referências a Anne-Christine Taylor reportam-se a uma conferência na Universidade de São Paulo (FFLCH), em 23 de novembro de 2011. Para outro estudo sobre os diálogos cerimoniais jívaro, consultar Gnerre (1986). 
“Assim! Irmão! Eu Estou! Em alerta!

Assim! Eu! Estou! Em alerta!

Meu irmão! Vá! Disse!

Assim! Eu! Irei!

Vá! Visitar! Os parentes!

Assim! Irmão mais velho! Pediu!

Irmão mais velho! Pediu! Para levar! A notícia!

Para fazer! Eles sofrerem! Eu vim!

Com! Essa espingarda! De verdade! Capitão!

Mas eu! Como eles! Eu faço!

Meu irmão! A guerra! Me ensinou!

Com ele! Os caminhos! Percorri!

E agora! Claramente! Falou!

Sabendo! Percorrer! Os caminhos!

Para! Levar! A guerra!

Assim! Irmão! Eu vim!"

Estes são então revidados da seguinte maneira pelo interlocutor $B$ :

“E eu! Irmão! Também! Estou aqui!

Eu! Sendo! O mais velho! Pelos caminhos! Eu vou!

Eu! Vamos ver! Pelos caminhos! Levo vocês!

Irmão! Meus antepassados! Também! São valentes!

Assim dito! Eu também! Em alerta! Estou!

Minhas palavras! Minhas! Estão cheias! De vigor!

Que a guerra! Seja! Assim! Eu digo!..."

Eis novamente a figura retórica do caminho (caminho como trajeto, como conduta ou ética; caminho como metáfora de relação de parentesco), constante no alto Xingu e presente, também, entre os marubo e outros tantos povos das terras baixas. Vale, no entanto, dedicar maior atenção ao penúltimo verso acima ("Minhas palavras! Minhas! Estão cheias! De vigor!”), que sintetiza a característica sobre a qual falávamos: não se trata exatamente de inexistência da função referencial, mas, antes, de um predomínio da função performativa, que corresponde à maximização da potência do falante. Essa potência é algo essencial ao ethos guerreiro jívaro e à aliança entre grupos locais. Vejamos o que diz Descola:

“Conversação cerimonial, torneio verbal coreografado preparando para o corpo-a-corpo, justa das vontades onde é expresso o valor de cada um - o anemat é tudo isso. Mas é também um dos raríssimos ritos coletivos que essa sociedade individualista criou para si, um rito de enfrentamento em que a 
celebração de uma união provisória só parece possível às custas de um inimigo comum. Estar junto, para os Achuar, é antes de tudo estar junto com alguns, contra alguns outros, numa coagulação efêmera do vínculo social, reunião de circunstância só permitida pela sede de vingança e o atrativo de uma façanha. O anemat traz à tona essa agregação e lhe dá consistência, num movimento em três etapas que recompõe de forma mimética as diferentes fases de um conflito" (Descola 2006: 433).

Estão aí colocados alguns indícios da natureza desse coletivo possível almejado pelo ritual jívaro. Essa provisoriedade da aglutinação coletiva é de fato bastante sugestiva. Distinta do mito da universalidade do coletivo, precisamente o mito da democracia, ela antes encaminha sua orientação pela posicionalidade. Algo similar ocorre também entre os marubo (falantes de pano da Amazônia ocidental), nas circunstâncias em que são realizados os tsãiki, diálogos cerimoniais bastante semelhantes aos dos jívaro acima mencionados. A capacidade de realizar um tsãiki indica maturidade intelectual e política de um homem tsãikiya ("o discursador"), que não necessariamente coincide com a figura do chefe de uma maloca ou grupo local, o kakaya. Este, no entanto, será reconhecido como um exímio cantador de $t$ ãaiki, ainda mais reconhecido se sua performance for mais firme, mais longa e mais incisiva do que a de seus potenciais interlocutores. Os tsãiki podem ser realizados em reuniões políticas diversas, inclusive naquelas em que lideranças marubo participam de encontros multiétnicos, já que eles constituem a principal demonstração da maximização política da pessoa e, também, uma demonstração de ese, ensinamento. ${ }^{6}$

Um de seus ambientes preferenciais, no entanto, são as festas tanámea, nas quais um determinado chefe local decide convidar parentes afins para sua casa por conta de uma colheita especialmente farta de banana e de macaxeira. Ornamentada com adornos e pinturas corporais, mais toda uma série de armamentos, uma comitiva da aldeia anfitriã, liderada por seu chefe, percorrerá os caminhos que ligam as aldeias (neste caso, do alto rio Ituí) e será recebida em cada uma delas pelos outros chefes locais. Aguardando no exterior da maloca, a comitiva é convidada a entrar e a se acomodar nos bancos paralelos masculinos (os kenã) situados em uma das duas entradas - o ambiente político e diplomático por excelência entre os marubo, no qual, diga-se de passagem, também são realizadas as visitas dos espíritos através dos corpos dos pajés romeya. Trata-se aí de uma coincidência espacial que atesta, mais uma vez, a proximidade entre a política da fala de chefe e a diplomacia sociocós-

6 Os tsãiki, no entanto, não são ensinados na escola, mesmo que de forma abreviada, e não estão sujeitos, ao menos por enquanto, a processos de patrimonialização, tal como no caso achuar (cf. Taylor, conferência referida; Gnerre 1986: 307). Ainda assim, são um item de destaque no reconhecimento de uma identidade marubo e uma das expressões exemplares do "nosso jeito" (noken tanáti), da "palavra dos nossos antepassados" (noken shenirasin vana). 
mica do xamanismo, de acordo com os estudos recentes de Guerreiro (2015) e Luciani (2017). Num determinado momento, depois de algumas conversas sobre amenidades, o chefe da maloca visitada se levanta, adota uma postura corporal rígida, posta-se diante de seu interlocutor e inicia seu tsãiki, que será em seguida replicado pelo chefe da comitiva visitante. Outros homens mais jovens são estimulados a participar do duelo verbal que, aqui como no caso jívaro, não possui vencedores ou perdedores e também se desenvolve em uma horizontalidade (ao menos provisória) entre falantes que partilham da mesma referência a um passado prototípico. No trecho abaixo, traduzido e editado por mim, encontramos novamente todas aquelas características formais acima destacadas (fragmentação das frases, discurso genérico alusivo, minimização dos contornos subjetivos, paralelismo, uso de evidenciais, ritmo marcado e pontuado pelos vocalizes, tom alto e firme, etc.). ${ }^{7}$ Ele se refere a um tsãiki elaborado pelo chefe e pajé Antonio Brasil Tekãpapa, endereçado ao seu afim Rominpa, que ali chegava com o objetivo de oficializar o convite para sua festa:

\begin{tabular}{|c|c|}
\hline “eeeña! & $e e e \tilde{a}$ \\
\hline noken shenirasin & nossos antepassados \\
\hline$e e e \tilde{a}$ & eеeã \\
\hline naivo vana & essas palavras \\
\hline vana akin & palavras diziam \\
\hline vana iniki & palavras proferiam \\
\hline mato ninkanmai & para vocês escutarem \\
\hline mato akavo & para vocês faziam \\
\hline matõ kopinãnã & para que revidassem \\
\hline eеe $\tilde{a}$ & eеe $\tilde{a}$ \\
\hline neskákin chinãi & assim pensei \\
\hline shokosho & juntos reunidos \\
\hline eeeã & eеẽ̃ \\
\hline еeег̃ & eеeã \\
\hline noke vake kanimai & $\begin{array}{l}\text { nossos filhos criamos } \\
\text { assim fazemos }\end{array}$ \\
\hline
\end{tabular}

7 Os tsãiki quebram a métrica tradicional das artes verbais pano, de quatro sílabas métricas por verso, e a substituem por uma oscilação entre duas e três sílabas fortes, com altura ascendente no final. Por conta disso, a estrutura gramatical das fórmulas verbais, perfeitamente encaixada à métrica tradicional de outros cantos, tais como os saiti (Cesarino 201 1, 2013), termina por se adaptar ao novo padrão rítmico e criar uma distribuição de unidades da frase entre as linhas que parece ser específica desse gênero verbal. Pela natureza da presente argumentação, optei por não apresentar aqui a tradução segmentada do tsãiki acima analisado. O leitor interessado em tais detalhes de minhas traduções poderá consultar outros trabalhos sobre cantos e narrativas marubo (Cesarino, Marubo Cherõpapa Txano e Marubo 2017; Cesarino 2018). Observo, ainda, que a presente escrita ortográfica do marubo opta por utilizar a letra $n$ para as nasais (como em ninkan, "escutar"), outrora grafadas por mim usando o til. 


\begin{tabular}{|c|c|}
\hline naivo chinã & esse pensamento \\
\hline viakinmai & transmitimos \\
\hline atõ oin & quando visitamos \\
\hline nõ akatõ & assim fazemos \\
\hline naivo vana & essa palavra \\
\hline naivo vanarao & essa palavra mesmo \\
\hline$e е e \tilde{a}$ & eеẽ̃ \\
\hline shavorasinniki & mulheres todas \\
\hline ato shokotani & todas juntas \\
\hline vanaki & devem dizer \\
\hline mato ninkanmai & para vocês escutarem \\
\hline apawavo & antigamente \\
\hline$i k i$ & assim era \\
\hline noke vanashoi & dizemos a vocês \\
\hline noke akavõ & assim fazemos \\
\hline vake kanimai & crianças criamos \\
\hline nõ akatõ & assim fazemos \\
\hline eеẽ̃ & eeẽ̃ \\
\hline kokanisho & do tio materno \\
\hline naivo vana & essa palavra \\
\hline vana iniki & palavra mesmo \\
\hline mato oinmai & quando visitamos \\
\hline txaitxovõ & cunhados todos \\
\hline papãvõ & tios paternos todos \\
\hline eeẽ̃ & $e е e \tilde{a}$ \\
\hline matõ vana yosina & palavra aprendem \\
\hline shokosho & juntos reunidos \\
\hline txaitxovo & cunhados todos \\
\hline naivo vana & essa palavra \\
\hline vana ikirivi & a palavra mesmo \\
\hline noke oinmai & quando visitamos \\
\hline noke akavo & assim dizemos \\
\hline naivo vana & essa palavra \\
\hline vana niakeshõ & com a palavra vivendo \\
\hline vana aki & a palavra \\
\hline atõ ninkãmai & eles escutam \\
\hline ea atõ anõ & eu os ensino \\
\hline eeea & eеẽ̃ \\
\hline$i k i$ & é verdade \\
\hline eеẽ̃ & еeе̃̃ \\
\hline$e e e \tilde{a}$ & eеẽ̃ \\
\hline neská atõ & assim eles \\
\hline
\end{tabular}




\begin{tabular}{|c|c|}
\hline atõ imainnõ & eles seguem \\
\hline eеẽ̃ & eeẽ̃ \\
\hline eеẽ̃ & eeẽ̃ \\
\hline$e е e \tilde{a}$ & $e e e \tilde{a}$ \\
\hline ato taketi & os seus irmãos \\
\hline vanainaki & vão mesmo dizendo \\
\hline matõ oinmai & quando visitamos \\
\hline matõ ninkãmai & quando escutamos \\
\hline en akatõ & eu assim faço \\
\hline vevokeki & mais velho sou \\
\hline ea ointani & quando visito \\
\hline vanaai & eu vou dizendo \\
\hline iki atõ imai & a eles digo \\
\hline ato aki & assim tenho feito \\
\hline en apawatõki & tal como antigamente \\
\hline ea miaka & eu digo a você \\
\hline vana neska aka & palavra como essa \\
\hline vevo kaniavo & os antes nascidos \\
\hline noke shenirasin & nossos antepassados \\
\hline shavo ninivarãsh & mulheres traziam \\
\hline revomashõrivi & para se espalharem \\
\hline anõ vakeya & e filhos criarem \\
\hline atõ vana yosi & palavra ensinavam \\
\hline awen mera shavovo & e suas irmãs \\
\hline atõ vana yosi & palavra ensinavam \\
\hline apawatõki & tal como antigamente \\
\hline nõ akatõ & nós ensinamos \\
\hline nõ neská & assim fazemos \\
\hline noke neskai & assim somos \\
\hline noken vevokevõ & nossos antepassados \\
\hline noken vevokevõ & nossos antepassados \\
\hline anõ yosinya & para aprender \\
\hline vana viakeshõ & palavras traziam \\
\hline eеẽ̃ & eеẽ̃ \\
\hline eеe $\tilde{a}$ & eеeã \\
\hline aská atõ & assim faziam \\
\hline inaki & é verdade \\
\hline atõ ninkãmai & eles escutavam \\
\hline nõ shokoatõ & e assim vivemos \\
\hline nõ neskái & assim fazemos \\
\hline$i k i$ & é verdade \\
\hline noke chinãmai & nosso pensamento \\
\hline
\end{tabular}




\begin{tabular}{|c|c|}
\hline vevokeaki & antepassados \\
\hline $\operatorname{china\tilde {i}}$ & pensavam \\
\hline nõ shokoatõro & e então nos reunimos \\
\hline ato chinãshoi & o pensamento deles \\
\hline en akatõ & eu mesmo sigo \\
\hline txipo kanini & os mais novos \\
\hline txipo kanini & os mais novos \\
\hline eeẽ & eeẽ̃ \\
\hline eеẽ̃ & $e е e \tilde{a}$ \\
\hline vari shavo ninivarãi & mulheres-sol trazem ${ }^{8}$ \\
\hline atõ shokoatõ & com elas vivem \\
\hline naivo vana & e essa palavra \\
\hline vana naroya & palavra imitam \\
\hline mato ninkãmai & para que escutem \\
\hline$e e e \tilde{a}$ & eeẽ̃ \\
\hline$e e e \tilde{a}$ & eеẽ̃ \\
\hline vevokesho & antepassados \\
\hline eеẽ̃ & 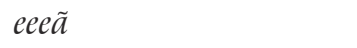 \\
\hline ееeа̃ & $e e e \tilde{a}$ \\
\hline eеẽ̃ & $e е e \tilde{a}$ \\
\hline ato pari & os que primeiro \\
\hline kanisho & cresceram \\
\hline naivo vana & essa palavra \\
\hline ikivõ & é verdade \\
\hline ato ninkãa & eles escutavam \\
\hline nõ kaniatõ & e assim crescemos \\
\hline eeẽ̃ & eeẽ̃ \\
\hline nõ neskámainnõ & agora nós \\
\hline naivo vana & essa palavra \\
\hline viaki & trazemos \\
\hline eеẽ̃ & eеẽ̃ \\
\hline noke chinãmanã & em nosso pensamento \\
\hline$i k i ”$ & é verdade \\
\hline
\end{tabular}

Os chefes (kakaya) são também donos de malocas (shovõ ivo), pertencentes a distintos grupos locais e a distintos nawavo, os segmentos da sociedade marubo que se relacionam entre si por um sistema de tipo kariera (membros do Povo Sol são cunhados do Povo Azulão, que são tios maternos do Povo Japó, que são tios paternos do Povo Arara, e assim por diante) (Melatti 1977). 
Até onde se sabe, esses nawavo guerreavam entre si em meados do século XIX até que, por conta da pressão da exploração da borracha e da atuação de um poderoso chefe-pajé (João Tuxáua), passaram a formar uma nova sociedade articulada através de tais relações de parentesco (essa que, posteriormente, viria a ser conhecida como Marubo). ${ }^{9}$ Ao longo do século XX, a atuação de João Tuxáua e de outros pajés poderosos terminou por transformar uma inclinação ao conflito entre tais parcialidades numa disposição social pacífica, marcada pela realização periódica de festivais, pela troca de conhecimentos e pelo casamento. Os atuais marubo costumam, portanto, se diferenciar de seus antepassados através de tal contraste: os antigos "cresciam junto guerreando" (pakayai kanisho), ao passo que agora as pessoas "crescem juntas pensando" (chinãyai kanisho). Para que isso ocorra, é essencial que sejam realizados rituais tais como o tanámea, ao longo dos quais costumam ser entoados os tsãiki.

O que ocorre na execução de tais falas? Como se disse, elas não são uma troca efetiva de opiniões ou uma expressão de reflexões sobre algum acontecimento (mítico ou atual), coisa que, entretanto, os Marubo costumam fazer com frequência nos momentos que se seguem à execução de um tsãiki, nos quais acontecem os acordos diplomáticos propriamente ditos. Se os tsãiki (e outros diálogos cerimoniais tais como os vistos acima) não dizem propriamente nada de novo, se não implicam em uma negociação efetiva, e tudo isso propositadamente, eles parecem existir então para conferir uma dimensão estética àquele acordo tácito e àquela ética da palavra a que me referi anteriormente. Daí o sentido da imitação e do espelhamento que constitui a variação entre distintas performances. ${ }^{10}$ Não se trata exatamente de adicionar

9 Ver Ruedas (2001) e Welper (2009) para mais informações sobre a etno-história e a política marubo.

10 Diz Clastres: "Mas evidentemente prestígio não significa poder, e os meios que o chefe detém para realizar sua tarefa de pacificador limitam-se ao uso exclusivo da palavra: não para arbitrar entre as partes opostas, pois o chefe não é um juiz e não pode se permitir tomar partido por um ou por outro; mas para, armado apenas de sua eloquência, tentar persuadir as pessoas da necessidade de se apaziguar, de renunciar às injúrias, de imitar os ancestrais que sempre viveram no bom entendimento. Empreendimento cuja vitória nunca é certa, aposta sempre incerta, pois a palavra do chefe não tem força de lei." (1982: 144 - o primeiro itálico é meu, o segundo do original). Não se trata com isso de dizer que não há "poder" nas terras baixas, mas sim que ele se orienta de outra forma e que não parte do pressuposto da lei e de seu abuso. Ora, há quem diga o contrário; os próprios marubo poderiam dizer, por exemplo, que existe sim uma lei indígena e que essa lei é o nosso ese (conhecimento, ensinamento). Isso, porém, não implica em uma equivalência de sentido com o regime jurídico moderno e se torna uma fonte potencial de equivocidades tradutórias (Castro 2004). Ruedas oferece um bom exemplo disso na seguinte passagem dedicada aos marubo do rio Curuçá (alto Ituí): “'My father is going to give us ese vana,' his son said. Vana means 'words', but I did not understand ese, so I asked him to translate it for me. He replied that it means lei, Portuguese for 'law'. I later asked another native speaker, who told me that ese means costume, Portuguese for 'custom,' I translate ese vana loosely as 'lecture on social relations'” (Ruedas 2002: 476). Ora, qual é a qualidade de tais lições sobre as relações sociais? Precisamente, aquela acima [continua] 
uma informação distinta na fala seguinte, mas sim de replicar o mesmo ou de deslocá-lo para outra posição. Em outros termos, os diálogos cerimoniais são empregados para simetrizar posições em uma cartografia de forças políticas, para mostrar que essa simetria sempre existiu e sempre existirá como um pano de fundo para que as subsequentes assimetrias se desenvolvam (aquelas decorrentes da maior ou menor influência deste ou daquele chefe sobre determinado conjunto de grupos locais). ${ }^{11}$ Sem a garantia desse pano de fundo, a sociedade tenderia a se esgarçar e a se dispersar em uma miríade de parcialidades desconectadas. $\mathrm{Na}$ ausência de um centro capaz de reunir as posições de parentesco em torno de uma abstração (a abstração do comum), algo deve ser capaz de garantir a integridade das redes sociais a partir de sua própria fluidez molecular, de sua conectividade pelas relações de vizinhança, de sua instabilidade constitutiva. Veiculada pelas palavras de chefes, é a referência a um passado prototípico, seja por um contraste negativo ou positivo com relação ao presente, que parece garantir a continuidade dos vínculos entre grupos locais.

A política negociada pelos donos/chefes não elege representantes, não se vincula a monarcas e outras figuras da verticalidade. ${ }^{12}$ "A sociedade primitiva", dizia Clastres, "é o lugar da recusa de um poder separado, porque ela própria, e não o chefe, é lugar real do poder” (1982: 108). De certa forma, é isso que os discursos cerimoniais parecem indicar: não a convergência do poder na figura isolada do chefe, mas em sua capacidade de encenar a continuidade das conexões de vizinhança e da ética dos antepassados. Um dono/chefe pode aglutinar

[continuação] anunciada por Clastres e pelos diálogos cerimoniais destacados ao longo deste texto: a imitação/manutenção dos vínculos estabelecidos pelos ancestrais. Veja ainda a seguinte passagem de Ruedas, na qual o autor mais uma vez destaca o papel da ese vana na política marubo: "The ideal shovo ivo [dono de maloca] is eseya [sábio, respeitoso, cheio de ensinamentos], that is, ese is one of his qualities, he has ese; he not only has knowledge but proper behavior and ability to speak ese vana. One elder told me that the inhabitants of a shovo needed the ese vana of a shovo ivo; without it the prosperity of the shovo would deteriorate. Hence an effective shovo ivo must regularly dispense ese vana. In this way, the shovo ivo monopolizes the legitimacy of authoritative discourse in the field of social relations" (Ruedas 2002: 477). Mais do que monopolizar tal legitimidade e autoridade, o dono de maloca eseya é também aquele que aglutina as parcialidades potencialmente dispersas entre si, tal como um corpo aglutina duplos ou componentes da pessoa (vaká, yochin), cuja desconexão implicaria na morte da pessoa, uma espécie de correlato da morte da sociedade. Para as relações de dispersão/aglutinação envolvidas nas figuras dos donos/mestres e suas replicações em escalas diversas, ver Cesarino (2010) para os marubo e Costa (2010) para os kanamari.

ll Ver Ruedas (2001) para um estudo detalhado sobre a política dos donos de maloca e chefes marubo. Exceto no que se refere à sua leitura apressada de Clastres (o fato de que o discurso do chefe [e sua figura como um todo] não possa ser um ponto de consolidação de poder não quer dizer, para Clastres, que ele inexista nas sociedades das terras baixas, mas sim que recai sobre a sociedade e mutatis mutandis sobre o vínculo parentesco), as conclusões do autor em tal artigo corroboram as minhas: os gêneros de discurso são peças centrais para a constituição de relações políticas de influência; eles engendram relações de poder que são distintas daquelas pressupostas pelo Ocidente democrático.

12 Para estudos sobre os donos/mestres nas sociedades das terras baixas, consulte Castro (2002), Fausto (2008), Costa (2010) e Cesarino (2010). 
outros, o que equivale à extensão de seu ponto de vista sobre o dos demais (Cesarino 2010), mas isso não implica na instituição de uma coletividade de tipo democrática e no reconhecimento de outrem como uma pessoa portadora de direitos e deveres garantidos pela lei. A diferença de um dono/chefe com relação a seus outros não é uma diferença extensiva, geométrica, mas intensiva. ${ }^{13}$ Ela deve ser demarcada e garantida por uma performance corporal e vocal, na qual ambos os sujeitos locutores emparelham as suas posições e reiteram o vínculo estabelecido pelas dinâmicas do dom e do parentesco.

\section{A POLÍTICA DO VÍNCULO}

Em dois artigos recentes sobre as falas de chefe ameríndias, Luciani (2017) e Guerreiro (2015) enfatizam paralelos entre tais eventos verbais e o xamanismo, nem sempre levados em consideração pelos especialistas. Para Luciani, as falas cerimoniais wayamou dos yanomami "se valem, na esfera intra-humana, de alguns recursos metafóricos e dêiticos que se tornaram lugar comum nas análises das negociações xamânicas inter-específicas" (Luciani 2017: 210). É neste sentido que, para o autor, humanos passam a ser tratados de maneira similar aos espíritos em tais eventos verbais, assim sugerindo "uma estética política comum que atravessa fronteiras ontológicas" (Luciani 2017: 210). Guerreiro, por sua vez, referindo-se às considerações de Beatriz Perrone-Moisés (2012: 10) sobre o assunto, para quem as figuras políticas ameríndias se moveriam "na relação espacial entre polos, sem se fixarem jamais em um ou outro deles", enfatizará o papel de substituto do chefe orador kalapalo com relação aos seus antepassados. Sua reflexão associa a posição de mediação da chefia com a teoria da quimera elaborada por Carlo Severi (2006), tornando compreensível "a performance ritual [como um] arranjo de duas percepções contraditórias do chefe, um agente político dotado de uma estética propriamente quimérica” (Guerreiro 2015: 78). Assim, para Guerreiro, uma estética apropriada é produzida para dar conta da "dualidade constitutiva da pessoa da chefia", para que se torne perceptível a eficácia de tais eventos pautados por uma forma de relação "jamais simétrica, mas sim hierárquica” (Guerreiro 2015: 79). Ao produzir uma imagem de chefes falecidos, a performance xinguana poderia assim ser compreendida através da noção de máscara acústica, desenvolvida por Severi para tratar dos aspectos ontologicamente paradoxais reunidos na figura de xamãs. É dessa forma que Guerreiro consegue compreender o papel mediador da oratória kalapalo: "essas falas refletem (e pretendem atuar sobre) os desafios relacionados aos efeitos desagregadores e às transformações representadas

13 “S’il y a une 'géometrie' primitive (proto-géometrie), c'est une géometrie opératoire où les figures ne sont jamais séparables de leurs affections...” (Deleuze e Guattari 1980: 258). Para a instauração inversa da geometria política, ver o estudo clássico de Lévêque e Vidal-Naquet (1997 [1964]). 
pela bruxaria, pelos inimigos e pelos espíritos perigosos que são os brancos. Clastres estava certo: a fala do chefe não produz ou demanda leis, mas tem uma grande capacidade reflexiva, e é disto que ela ganha ao menos uma parte de sua força" (Guerreiro 2015: 81).

É de fato algo similar que ocorre entre os marubo, cuja performance da chefia também evidencia, isto é, também produz uma estética específica para a replicação da imagem de chefes falecidos. Meu uso intencional do termo replicação, entretanto, vem aqui oferecer uma alternativa à noção de representação de que se valem Severi e Guerreiro, conceitualmente subsumida na noção de substituição, utilizada por este último autor como tradução da noção kalapalo de itüpohongo (Guerreiro 2015: 65). Quais seriam, entretanto, os mundos e os pressupostos políticos envolvidos nesta ou naquela forma de representação e substituição? Qual seria, afinal das contas, a política em questão? Não tratamos, evidentemente, dos mesmos pressupostos subentendidos pela noção moderna de representação política e seu respectivo regime legal, como bem apontava Clastres. Tampouco postularia ela alguma salvaguarda do comum (koiné) ou do meio (meson), como pretendiam as bases da democracia grega (Wolff 1983; Dardot e Laval 2017). Falta, portanto, definir de maneira mais clara os contornos da política envolvida em tais regimes de enunciação, fundamental para que se compreenda melhor a sua respectiva produção poética. Se a associação entre fala de chefe e xamanismo é efetivamente produtiva, como sugerem os especialistas, então quais concepções de política e de poder se projetariam nessa produção de vínculos entre afins, que parece ser homóloga, ainda mais, àquela estabelecida entre humanos e extra-humanos?

A política, dizia Jacques Rancière, "não é feita de vínculos de poder, mas sim de vínculos de mundos" (1995: 67). Mas de qual política fala o filósofo? Não exatamente daquela postulada por outros mundos (como os ameríndios), em princípio alheios àquele que definiu esta "política" assim naturalizada e universalizada a partir do Ocidente. "O dano [tort] fundador da política", diz Rancière em sua pressuposição de universalidade, "é de uma natureza bem particular [...]. Ele se distingue em primeiro lugar do dano jurídico objetivável enquanto vínculo entre partes determinadas, regulável por procedimentos jurídicos apropriados. Isso é devido simplesmente ao fato de que essas partes não existem antes da declaração do dano" (Rancière 1995: 64). É apenas a partir da tomada de consciência das partes que surge a subjetivação política, assim capaz de "produzir um múltiplo que não estava dado na constituição policial da comunidade, um múltiplo cuja conta se coloca como contraditória com a lógica policial. "O povo", segue o autor, "é o primeiro desses múltiplos que separam a comunidade dela mesma, a inscrição primeira de um sujeito e de uma esfera de aparência de sujeito a partir da qual outros modos de subjetivação propõem a inscrição de outros 'existentes', de outros sujeitos do litígio político” (Rancière 1995: 60). Não por acaso, é aí que incidirá o papel 
da linguagem na política, "estética em seu princípio" (Rancière 1995: 88) e dependente, na modernidade, da "multiplicação das operações de subjetivação que inventam mundos de comunidade, eles mesmos mundos de dissenso, bem como desses dispositivos de demonstração que são, a cada vez, ao mesmo tempo argumentações e aberturas de mundo, abertura de mundos comuns - o que não quer dizer consensuais -, de mundos nos quais o sujeito que argumenta é contado como argumentador" (Rancière 1995: 89). A estrutura do desentendimento [mésentente] derivaria, assim, de um paradoxo fundamental da política ocidental (moderna e antiga): a recusa em reconhecer como existente, por alguma das partes, o litígio e o próprio objeto do litígio (Rancière 1995: 84-85).

Como conceber, em nosso caso presente, uma política não derivada de tal dano fundador do Ocidente que, para Rancière, é algo mais do que a luta de classes, mas sim a impossibilidade de instauração de um poder capaz de mediar a comunidade (Rancière 1995: 33)? Ora, a inexistência desse poder mediador entre as sociedades ameríndias (das terras baixas da América do Sul) não é a consequência paradoxal da distinção das duas partes que fundamentam nossa política desde seus primórdios gregos: os pobres e os ricos (Rancière 1995: 30). As tentativas de instaurar uma ordem institucional que remende tal paradoxo tampouco assenta sobre uma forma de representação que produziria um pacto social e a instauração do comum. Não se trata, por um lado, de produzir uma manutenção policial do aparelho do Estado, nem, por outro, de fazer com que a política surja em suas brechas, ou seja, na interrupção provisória dos efeitos da exploração pela subjetivação das partes, pela tomada da argumentação e pela geração do desentendimento. Em suas falas, os chefes ameríndios não reiteram a ordem institucional, não arbitram desavenças entre partes, não recusam ou reivindicam o que parece ser objeto de litígio para uns ou para outros. Como vimos, ao replicarem seus antepassados, parecem reiterar que, a despeito de desacordos entre parentes, uma determinada forma de vínculo deve permanecer.

Os magníficos espíritos yovevo, dispersos em suas incontáveis multidões virtuais, costumam ser explicados pelos marubo como sendo também eles yora tsãikiya, ou seja, gente loquaz, capaz de proferir a sua oratória cerimonial. Medem também eles, portanto, a potência de sua posição ao se encontrarem com seus afins espalhados pelas socialidades replicadas pelos mais distintos patamares celestes e terrestres, bem como pelas mais distintas moradas que vemos como árvores e rios. A ética da dialogicidade se configura, assim, como uma tessitura sociocósmica permanentemente ativada e reiterada pela palavra poética. Trata-se, portanto, de um regime cosmopolítico no qual nas palavras prestam-se a conectar mundos múltiplos, como sugere Sztutman (2017) a partir de Isabelle Stengers, Pierre e Hélène Clastres. A ênfase provisória de uma posição assimétrica em um determinado encontro deverá servir para reiterar 
vínculos desde sempre existentes, pois, afinal, as pessoas já surgiram sendo capazes de viver em parentesco. Assim, os humanos - que, como bem anotava Franchetto acerca dos kuilkuro, vivem uma atualidade empobrecida com relação aos seus antepassados e espíritos - deixam de ser os atores e autores principais de sua política. Ao replicarem com as palavras fortes as mesmas falas de outrem, distribuídas de maneira indefinida no espaço e no tempo, é toda a centralidade e autonomia do sujeito político que se dissipa em uma queda em abismo. Inteiramente distinta daquele ato que inventava simultaneamente a cidade e o homem, a política ameríndia é também distante de seus danos e paradoxos. Ao modular a potência predadora enquanto evento ritual, ela garante, em sua estética apropriada, a possibilidade de existência do outro e de seus mundos possíveis. ${ }^{14}$

14 As diretrizes éticas do "bem viver" e da replicação do passado, que constituem os diálogos cerimoniais e que permeiam aquele acordo tácito da relação com outrem, como lidarão com as formas de sedimentação pela escrita, o registro abstrato das leis e constituintes, dos acordos entre pessoas? O estudo de Schavelzon (201 1: 1 18) sobre o processo de "incorporação, no direito estatal, de conceitos indígenas de terras altas e baixas" na Bolívia contemporânea poderia levar a uma extensão interessante dos argumentos aqui tratados. 


\section{BIBLIOGRAFIA}

CASTRO, Eduardo Viveiros de, 1986, Araweté: Os Deuses Canibais. Rio de Janeiro, Zahar/Anpocs. CASTRO, Eduardo Viveiros de, 2002, A Inconstância da Alma Selvagem. São Paulo, Cosac Naify. CASTRO, Eduardo Viveiros de, 2004, "Perspectival anthropology and the method of controlled equivocation", Tipití, 2 (1): 3-22, disponível em < https:/digitalcommons.trinity. edu/tipiti/vol2/iss l/l/ > (última consulta em fevereiro de 2020).

CESARINO, Pedro de Niemeyer, 2006, “De duplos e estereoscópios: paralelismo e personificação nos cantos xamanísticos ameríndios", Mana, 12 (1): 105-135, disponível em < http: //dx.doi.org/10.1590/S0104-93132006000100004 > (última consulta em fevereiro de 2020).

CESARINO, Pedro de Niemeyer, 2010 , "Donos e duplos: relações de conhecimento, propriedade e autoria entre Marubo", Revista de Antropologia, 53 (1): 147-199, disponível em < http: //www.revistas.usp.br/ra/article/view/27348 > (última consulta em fevereiro de 2020).

CESARINO, Pedro de Niemeyer, 2011 , Oniska: Poética do Xamanismo na Amazônia. São Paulo, Perspectiva/FAPESP.

CESARINO, Pedro de Niemeyer (org.), 2013, Quando a Terra Deixou de Falar: Cantos da Mitologia Marubo. São Paulo, Editora 34.

CESARINO, Pedro de Niemeyer, 2014, "A voz falível: ensaio sobre as formações ameríndias de mundos", Literatura e Sociedade, 19: 76-99, disponível em < http://www.revistas.usp. br/ls/article/view/97208 > (última consulta em fevereiro de 2020).

CESARINO, Pedro de Niemeyer, 2018, "Wenía: o surgimento dos antepassados. Leitura e tradução de um canto narrativo ameríndio (Marubo, Amazônia ocidental)", Estudos de Literatura Brasileira Contemporânea, 53: 45-99, disponível em < http://dx.doi. org/10.1590/2316-4018533 > (última consulta em fevereiro de 2020).

CESARINO, Pedro de Niemeyer, Armando Mariano MARUbO CHERÓPAPA TXANO, e Robson Doles Dionísio MARUBO, 2017, "Marubo", em Kristine Stenzel e Bruna Franchetto (orgs.), On This and Other Worlds: Voices from Amazonia. Berlim, Language Science Press, 139-162, disponível em < https://langsci-press.org/catalog/book/167> (última consulta em fevereiro de 2020).

CLASTRES, Pierre, 1982, A Sociedade contra o Estado. Rio de Janeiro, Francisco Alves.

COSTA, Luiz, 2010, "The Kanamari body-owner: predation and feeding in Western Amazonia”, Journal de la Société des Américanistes, 96 (1): 169-192, disponível em < https://journ als.openedition.org/jsa/1 1332 > (última consulta em fevereiro de 2020).

CUNHA, Manuela Carneiro da, 1998, "Pontos de vista sobre a floresta amazônica: xamanismo e tradução", Mana, 4 (1): 7-22, disponível em < http://dx.doi.org/10.1590/S010 4-93131998000100001 > (última consulta em fevereiro de 2020).

DARDOT, Pierre, e Christian LAVAL, 2017, Comum: Ensaio sobre a Revolução no Século XXI. São Paulo, Boitempo.

DÉLÉAGE, Pierre, 2009, Le chant de l'anaconda: L'apprentissage du chamanisme chez les Sharanahua. Nanterre, Société d'Ethnologie.

DELEUZE, Gilles, e Félix GUATTARI, 1980, Mille plateaux. Paris, Les Editions de Minuit.

DESCOLA, Philippe, 2006, As Lanças do Crepúsculo. São Paulo, Cosac Naify.

FAUSTO, Carlos, 2008, "Donos demais: maestria e domínio na Amazônia”, Mana, 14 (2): 329-366, disponível em < http://dx.doi.org/10.1590/S0104-93132008000200003> (última consulta em fevereiro de 2020). 
FRANCHETTO, Bruna, 2000, "Rencontres rituelles dans le Haut Xingu: la parole du chef", em Aurore Becquelin Monod e Philippe Erikson (orgs.), Les rituels du dialogue: Promenades ethnolinguistiques en terres amérindiennes. Nanterre, Societé d'Ethnologie: 481-510.

GNERRE, Maurizio, 1986, "The decline of dialogue: ceremonial and mythological discourse among the Shuar and Achuar of Eastern Equador", em Joel Sherzer e Greg Urban (orgs.), Native South-American Discourse. Berlim, Mouton de Gruyter, 307-343.

GUERREIRO, Antonio, 2015, "Political chimeras: the uncertainty of the chief's speech in the Upper Xingu", HAU, 5 (1): 59-85, disponível em < https://www.haujournal.org/ index.php/hau/article/view/hau5.1.004 > (última consulta em fevereiro de 2020).

HEURICH, Guilherme Orlandini, 2015, Música, Morte e Esquecimento na Arte Verbal Araweté. Rio de Janeiro, Museu Nacional/Universidade Federal do Rio de Janeiro, tese de doutorado.

LÉVÊQUE, Pierre, e Pierre VIDAL-NAQUET, 1997 [1964], Cleisthenes the Athenian. Nova Jérsia, Humanities Press.

LUCIANI, José Antonio Kelly, 2017, “On Yanomami ceremonial dialogues: a political aesthetic of metaphorical agency”, Journal de la Société des Américanistes, 103 (1): 179-214, disponível em < https://journals.openedition.org/jsa/14892> (última consulta em fevereiro de 2020).

MELATTI, Julio Cezar, 1977, "Estrutura social marubo: um sistema australiano na Amazônia”, Anuário Antropológico, 76: 83-120.

MESCHONNIC, Henri, 1982, Critique du rythme. Paris, Verdier.

PERRONE-MOISÉS, Beatriz, 2012, "Bons chefes, maus chefes, chefões: elementos de filosofia política ameríndia”, Revista de Antropologia, 54: 5-20.

RANCIÈRE, Jacques, 1995, La mésentente. Paris, Galilée.

RUEDAS, Javier, 2001, The Marubo Political System. Nova Orleães, Tulane University, tese de doutorado.

RUEDAS, Javier, 2002, "Marubo discourses genres and domains of influence: language and politics in an indigenous Amazonian village", International Journal of American Linguistics, 68 (4): 447-482, disponível em < https://www.jstor.org/stable/1265803 > (última consulta em fevereiro de 2020).

SCHAVELZON, Salvador, 2011, "Uma política ameríndia”, Cadernos de Subjetividade, 13: 109-120, disponível em < http://revistas.pucsp.br/cadernossubjetividade/article/view/38 $466>$ (última consulta em fevereiro de 2020).

SEVERI, Carlo, 2006, Le principe de la chimère. Paris, Editions Rue D’Ulm/Musée du quai Branly. SZTUTMAN, Renato, 2017, "When metaphysical words blossom: Pierre and Hélène Clastres on Guarani thought”, Common Knowledge, 23 (2): 325-344.

URBAN, Greg, 1986, "Ceremonial dialogues in South America", American Anthropologist, 88 (2): 371-386, disponível em < https://anthrosource.onlinelibrary.wiley.com/ doi/10.1525/aa.1986.88.2.02a00050 > (última consulta em fevereiro de 2020).

WELPER, Elena, 2009, O Mundo de João Tuxáua: (Trans)formação do Povo Marubo. Museu Nacional/Universidade Federal do Rio de Janeiro, tese de doutorado.

WOLFF, Francis, 1983, "Filosofia grega e democracia”, Discurso, 14: 7-48, disponível em $<$ http://www.revistas.usp.br/discurso/article/view/37901 > (última consulta em fevereiro de 2020). 